\title{
BMJ Will our junior doctors be ready for the OPen next major incident? A questionnaire audit on major incident awareness across three NHS Trusts in Wales
}

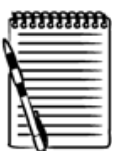

PRESS

RELEASE

To cite: Hobson JM. Will our junior doctors be ready for the next major incident? A questionnaire audit on major incident awareness across three NHS Trusts in Wales. BMJ Open 2011;1:e000061. doi:10.1136/bmjopen-2011000061

- Prepublication history for this paper is available online. To view these files please visit the journal online (http:// bmjopen.bmj.com).

Received 11 January 2011 Accepted 9 May 2011

This final article is available for use under the terms of the Creative Commons Attribution Non-Commercial 2.0 Licence; see http://bmjopen.bmj.com

${ }^{1}$ Department of Emergency, The Royal Gwent Hospital, Newport, UK

${ }^{2}$ The Orchard, Wrexham, UK

Correspondence to Dr Joseph M Hobson; hobsonjm@gmail.com

\author{
Joseph M Hobson ${ }^{1,2}$
}

\section{ABSTRACT}

Aim: The aim was to assess junior doctors' understanding of their role in the Major Incident Contingency Plan at their hospital, and to evaluate the effectiveness of a teaching intervention on increasing awareness.

Background: In this audit, 'junior doctor' refers to the first 2 years of work after qualifying from medical school. Once a major incident is confirmed, junior doctors should go to their ward, contact the senior nurse in charge and compile a list of the patients who could safely be discharged from the hospital. This action is standard across NHS Trusts in Wales.

Method: A questionnaire was given to 89 junior doctors across three NHS Trusts in Wales. It involved general aspects of a major incident, as well as ascertaining perceptions of their role as junior doctors. They then received formal teaching by Emergency Planning Faculty. Following this, a repeat questionnaire was completed.

Results: $91 \%$ felt they did not know what would be expected of them during a major incident; $47 \%$ would initially go to the Emergency Department; $27 \%$ were unclear where to go; $31 \%$ were unaware who to contact on hearing of a major incident; and $16 \%$ would telephone switchboard. Junior doctors believe their primary role would be triage (16\%); clerking in the emergency department (36\%); clerking in Medical Assessment Unit/Surgical Assessment Unit (17\%); and practical work (15\%). Only $3 \%$ would first go to their ward; $12 \%$ believe their primary role would involve patients on the ward; and only $1 \%$ would list patients for discharge. $90 \%$ of completed questionnaires included a request for teaching. Following teaching, $97 \%$ knew who to call, where to go and what to do during a major incident.

Conclusion: Junior doctors' awareness of major incidents within Wales was near absent prior to teaching. This teaching is vital to help ensure smooth running of the hospital on the day.

\section{BACKGROUND}

The Department of Health defines a major incident as 'any event whose impact cannot be handled within routine service

\section{ARTICLE SUMMARY}

Article focus

- Are junior doctors aware of their role during a major incident?

- How effective is a teaching intervention on improving awareness?

\section{Key messages}

- This audit is the first of its kind to assess the understanding of major incident roles within Wales.

- Awareness of major incidents was near absent prior to teaching.

- Teaching is highly effective, and the vast majority of junior doctors wish to learn about it.

Strengths and limitations of this study

- Three of the seven NHS Trusts in Wales were included in the audit. These Trusts were located in both the north and the south of Wales, giving a good reflection of major incident awareness across the country.

- A limitation of the audit was that the second questionnaire was completed within one day of the teaching; it did not assess the longer-term retention of this knowledge.

arrangements. It requires the implementation of special procedures by one or more of the emergency services, the NHS, or a Local Authority to respond to it."

Although only in its early stages, the twentyfirst century has already seen major incidents involving transport, industry, and terrorism, all of which have impacted on countless lives across the country. ${ }^{2-4}$ These events are not just memories in our past; the catalysts for major incidents are still present year on year. Currently the Home Office terrorism threat level is 'Severe'; this means that a terrorist attack is highly likely. ${ }^{5}$

On the day it happens, hospital staff are immersed in a highly intense and overwhelming environment. Limits on alreadystrained resources are pressed even further. 
Effective management within a hospital during this time is vital in suppressing the impact it will have on both the individuals affected, and society as a whole. Because of this, every hospital in the UK has a Major Incident Contingency Plan. Depending on the hospital, this plan can be found in departments, wards or online. Within this plan, every professional position in the hospital has a page dedicated to explaining their contacts, roles and responsibilities during a major incident; this is known as an action card. ${ }^{6-8}$

In this audit, 'junior doctor' refers to the first 2 years of work after qualifying from medical school. Once a major incident has been confirmed, they will be alerted via their pager to 'activate a full major incident response.' Their action card states they are to report to the Senior Nurse on the ward, assemble a list of all potential discharges, and manage existing patients on the ward. Should they be needed elsewhere, they will be contacted by a senior or by the Hospital Control Centre. The junior doctor should let their seniors know where they are, and if they need to contact a department it should go through the Hospital Control Centre. These actions are standard for Junior Doctors across NHS Trusts in Wales. ${ }^{6-8}$

Resources have been spent preparing policies on a coordinated response within a hospital to a major incident, but has this information been passed down to all the individual staff? Are staff aware of their roles during a major incident? Studies throughout the last 10 years have shown that despite continuing catastrophes within the UK, major incident awareness throughout hospitals is poor, and vital teaching is absent from most staff timetables. ${ }^{9-11}$

Through effective teaching, uncertainties during a major incident could be significantly eased if every staff member knew what was expected of them before that day arrived. At present, teaching on major incidents is not included in medical school or Foundation Year induction programmes in NHS Trusts in Wales.

\section{AIM}

The aim was to assess junior doctors' understanding of their role in the Major Incident Contingency Plan at their hospital and to evaluate the effectiveness of a teaching intervention on increasing awareness.

\section{METHOD}

A teaching session on major incidents was given to 89 junior doctors across three NHS Trusts in Wales (North Wales, Gwent Healthcare and Cwm Taf), this covered $14 \%$ of the total number of junior doctors in Wales.

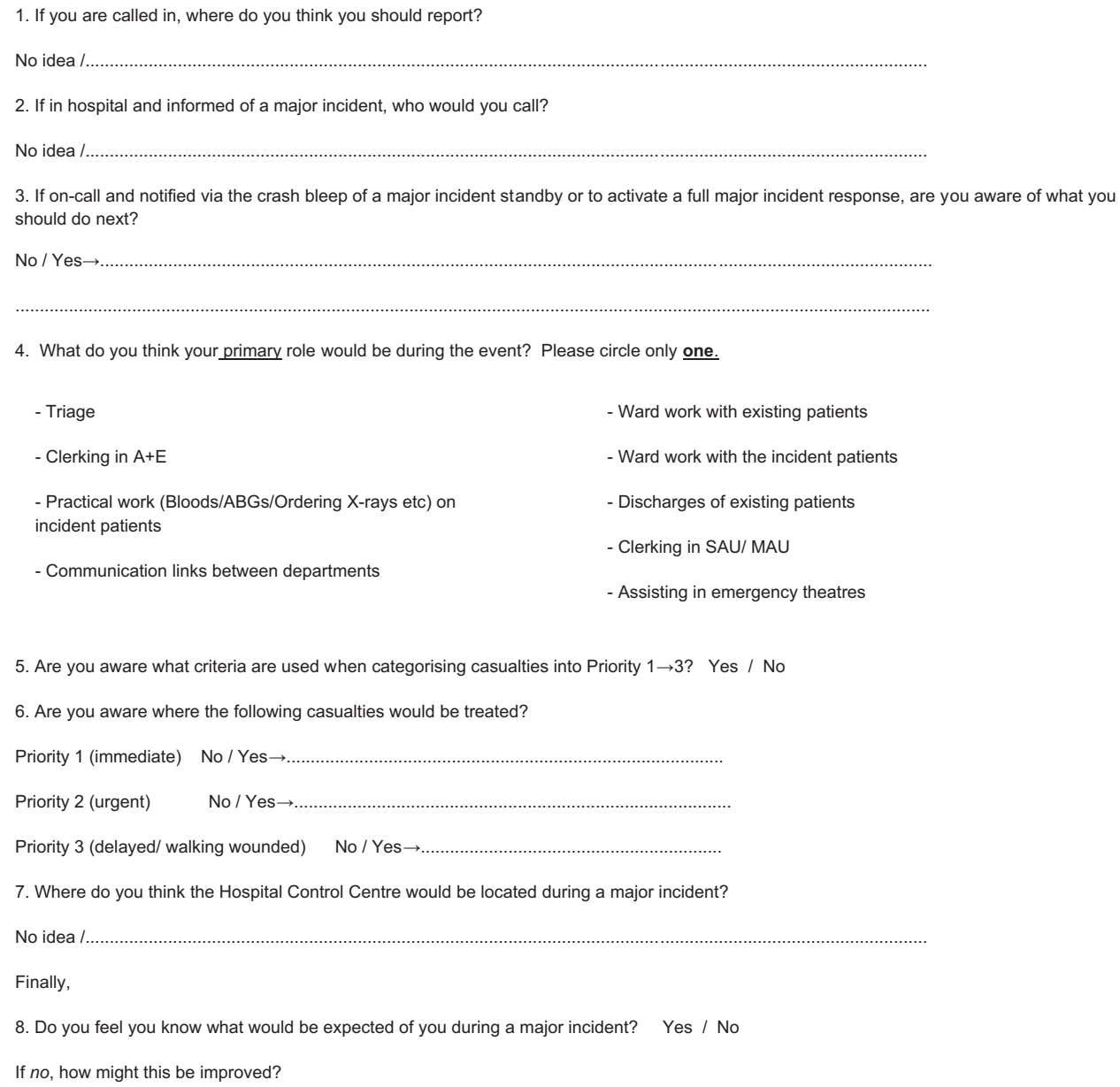


Before the teaching began, the junior doctors were asked to complete a questionnaire on the topic. This included 30 General Medical, 29 General Surgical, 13 Emergency Department (ED), and 17 Peadiatric Doctors. The questionnaire described a scenario whereby a hundred people were injured to varying degrees at a football stadium. Junior doctors were then asked the following questions:

The questionnaire was designed by the author solely for this research and was viewed by the Wrexham Maelor Hospital audit department. It involved general aspects of a major incident, as well as ascertaining perceptions of their role as junior doctors. After the questionnaire, the junior doctors received formal teaching by Emergency Planning Faculty. This included an ED consultant, Emergency Planning Manager and members of the Resuscitation Department. The teaching was in the form of PowerPoint presentations and table-top exercises. Following this, an identical repeat questionnaire was completed. All questionnaires were completed anonymously.

\section{RESULTS}

All 89 doctors completed the repeat questionnaire. On the day it happens, $93 \%$ of junior doctors felt they did not know what would be expected of them during a major incident.

Figure 1 shows that $31 \%$ per cent of junior doctors were unaware who to contact on hearing of a major incident; an additional 16\% would telephone switchboard.

Figure 2 illustrates that $47 \%$ of all the junior doctors would initially go to the ED; $12 \%$ would go to the Major Incident Control Centre; and 27\% were unclear where to go. No junior doctor would report to a general medical or surgical ward.

Figure 3 highlights the lack in awareness of roles during a major incident. Largely junior doctors believe their primary role would be triage $(16 \%)$; clerking in the ED (36\%); clerking in Medical Assessment Unit/ Surgical Assessment Unit (17\%); and practical work $(15 \%)$. Only $12 \%$ believe their primary role would

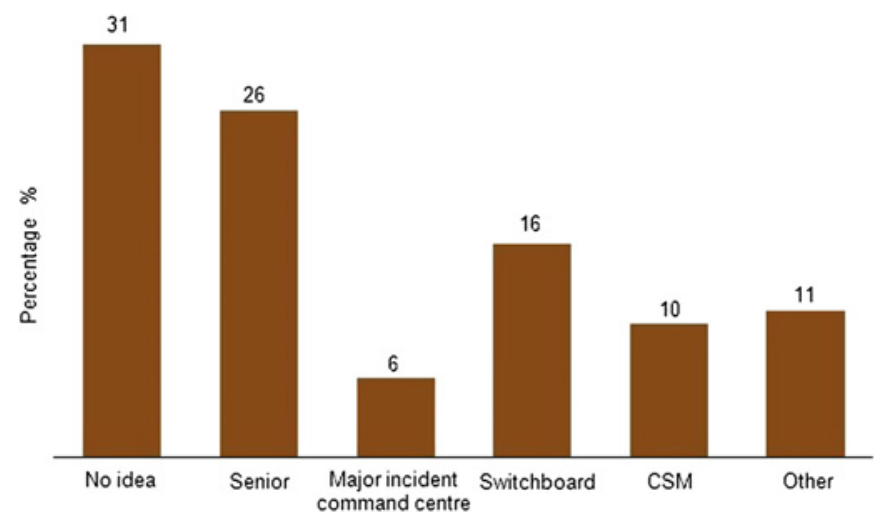

Figure 1 Who the junior doctors would call once being alerted of a major incident. CSM, Clinical Site Manager.

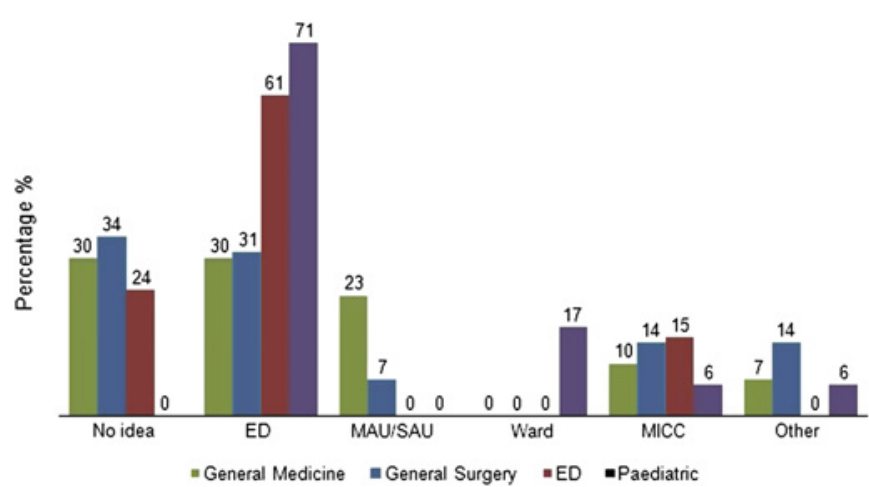

Figure 2 Where the junior doctors would report. ED, Emergency Department; MAU/SAU, Medical Assessment Unit/ Surgical Assessment Unit, MICC, Major Incident Control Centre.

involve patients on the ward; and only $1 \%$ would list patients for discharge.

No junior doctor knew how to prioritise casualties, and only $1 \%$ knew where in the hospital they would be managed. Ninety per cent of completed questionnaires included a request for teaching. Following teaching, $97 \%$ knew who to call, where to go and what to do during a major incident, as well as how to categorise and distribute casualties. This difference was statistically significant $(\mathrm{p}<0.001)$ on $\chi^{2}$ testing.

\section{DISCUSSION}

Results from the preteaching questionnaire show an alarming deficit in the awareness of junior doctors towards major incidents. This lack of understanding during a major incident will undoubtedly be highly detrimental to the efficient and safe management of the hospital on the day.

Uncertainties of roles and responsibilities by the junior doctor will increase their stress levels in an already-demanding situation; this could impair their ability to make safe decisions in the hospital. The results show that almost a third of junior doctors would have no idea who to call, and $16 \%$ would attempt to phone the hospital switchboard for instruction on how to precede once hearing of a major incident. Other suggestions of who they would call, that is the Major Incident Control Centre, would be on the presumption the doctor already knew the extension number and would not have to go through the switchboard: a switchboard that unknowingly to most would be shut down during a major incident, adding further uncertainty to the junior doctor.

It will be imperative during a major incident that the ED runs effectively, and is staffed with the appropriate number of trained individuals who know their role in the unit. The preteaching results demonstrate that almost a third of medical and surgical junior doctors in the hospital would attend the ED for instruction. This will undeniably cause disruption in the busy department and hinder the efforts of those who are intended to be there, 
Figure 3 Junior doctors' understanding of their primary role during a major incident. ED, Emergency Department; MAU/ SAU, Medical Assessment Unit/ Surgical Assessment Unit; WW, Ward Work.

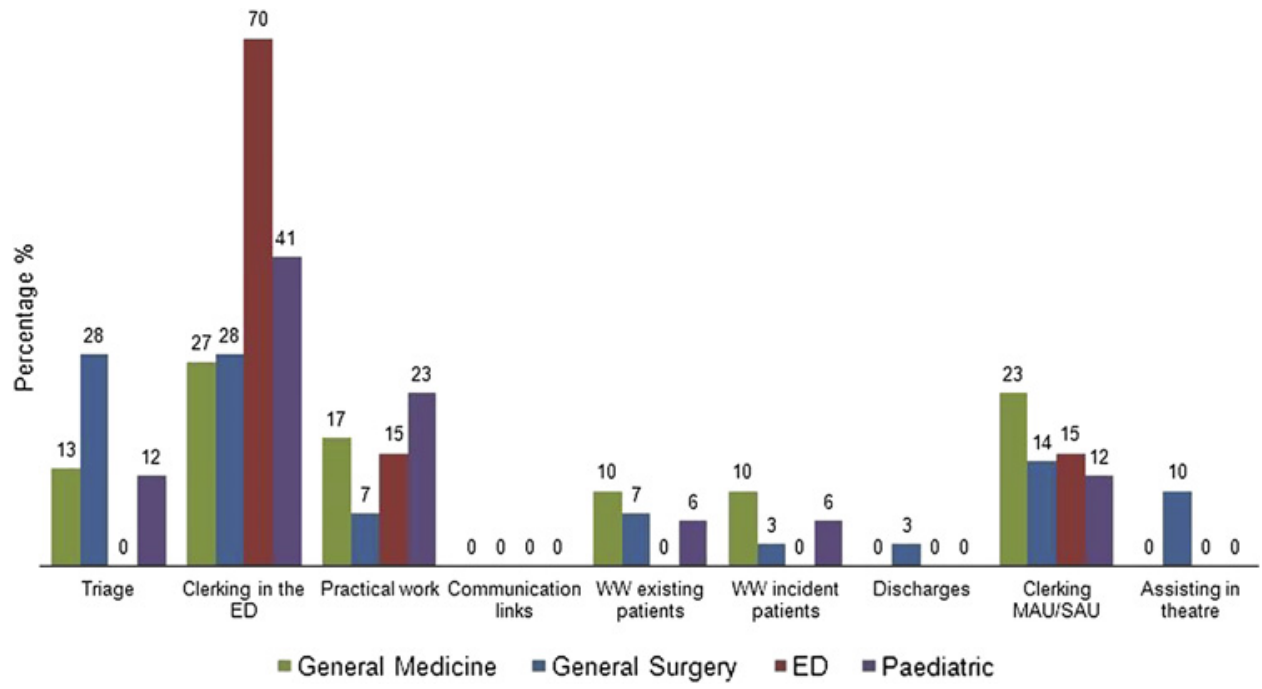

as well as waste valuable time when dispersing the junior doctors back to the appropriate location.

A highly concerning aspect of the preteaching statistics is the lack of junior doctors on the hospital wards. With no medical or surgical junior doctor attending the ward first, important responsibilities of the individual will not be completed, that is, discharge planning. The need to release beds for the large influx of new patients is crucial for the effective management of the hospital during a major incident. The results show that without appropriate teaching, 99\% of junior doctors would not create a discharge list. This would significantly obstruct the movement of patients from triage departments.

NHS trusts in Wales are not alone within the UK in regard to poor awareness during a major incident. ${ }^{9-13}$ Madge and colleagues designed a questionnaire in 2002 that showed medical staff lacked confidence in their role during a major incident. ${ }^{9}$ Studies by Graham in 1999 and by Wong 7 years later highlighted that major incident teaching is rarely compulsory or addressed in UK hospitals. ${ }^{10} 11$

In 2006, Carr demonstrated in a similar study that doctors in large London hospitals had a poor awareness of major incidents, but that this knowledge could be significantly improved with appropriate interventions. ${ }^{14}$ In contrast, Milkhu and colleagues showed that despite only $41 \%$ having read the major incident policy in full, $70 \%$ knew the correct immediate action to take if informed of major incident activation. ${ }^{12}$

With industrial factories, shipping ports, sports stadiums and increasing road and rail traffic, Wales is a country with numerous major-incident risks in parallel to that of London. This audit, the first of its kind in Wales, has highlighted the lack of awareness in junior doctors but also the value of teaching on major incidents.

This paper demonstrates that major-incident awareness is poor within NHS Trusts in Wales. Could this be due to the belief that it is a rare problem of other hospitals and that more routine topics are of greater importance. It is perhaps this innocence that prevents major-incident teaching being included into medical school teaching or Foundation Year induction programmes in NHS Trusts in Wales. The results from this study clearly show that major incident teaching is urgently needed among junior doctors. The results also show that teaching is highly effective, and the vast majority of junior doctors wish to learn about it.

\section{CONCLUSION}

Junior doctors' awareness of major incidents within NHS Trusts in Wales was near absent prior to teaching. This shortfall in knowledge could severely compromise a hospital's ability to provide optimal care for its patients. Teaching to all junior staff on their roles and responsibilities during a major incident is vital to help ensure smooth running of the hospital during this time. Staff unaware of their roles and responsibilities will turn a major incident into a major disaster.

Acknowledgements The author would like to thank S Fry, for data collection within Cwm Taf NHS Trust.

Competing interests None.

Contributors JMH is the sole author of the contribution.

Provenance peer review Not commissioned; externally peer reviewed.

Data sharing statement No additional data available.

\section{REFERENCES}

1. http://www.dh.gov.uk/prod_consum_dh/groups/dh_digitalassets/ @ dh/@en/documents/digitalasset/dh_4121236.pdf (accessed 9 May 2011).

2. http://www.guardian.co.uk/uk/2008/jan/17/world.theairlineindustry (accessed 5 Jul 2010).

3. http://news.bbc.co.uk/1/hi/uk/4517962.stm (accessed $5 \mathrm{Jul}$ 2010).

4. http://news.bbc.co.uk/1/hi/in_depth/uk/2005/london_explosions/ default.stm (accessed 5 Jul 2010).

5. http://www.homeoffice.gov.uk/counter-terrorism/current-threat-level (accessed 9 May 2011).

6. Cwm Taf NHS Trust. Major Incident Plan, Junior Doctor Action Card. 2009.

7. Gwent Healthcare NHS Trust. Major Incident Plan, Junior Doctor Action Card. 2005.

8. North Wales NHS Trust. Major Incident Plan, Junior Doctor Action Card. 2007. 
9. Madge SN, Kersey JP, Murray G, et al. Are we training junior doctors to respond to major incidents? A survey of doctors in the Wessex region. Emerg Med J 2004;21:577-9.

10. Graham CA, Hearns ST. Major incidents: training for on site medical personnel. J Accid Emerg Med 1999;16:336-8.

11. Wong K, Turner PS, Boppana A, et al. Preparation for the next major incident: are we ready? Emerg Med $J$ 2006;23:709-12.
12. Milkhu CS, Howell DC, Glynne PA, et al. Mass casualty incidents: are NHS staff prepared? An audit of one NHS foundation trust. Emerg Med J 2008;25:562-4.

13. Brennan L, Sage FJ, Simpson A. Major incident planning in South East Thames Region: a survey of medical staff awareness and training. J Accid Emerg Med 1994:11:85-9.

14. Carr ER, Chatrath P, Palan P. Audit of doctors' knowledge of major incident policies. Ann R Coll Surg Engl 2006;88:313-15. 